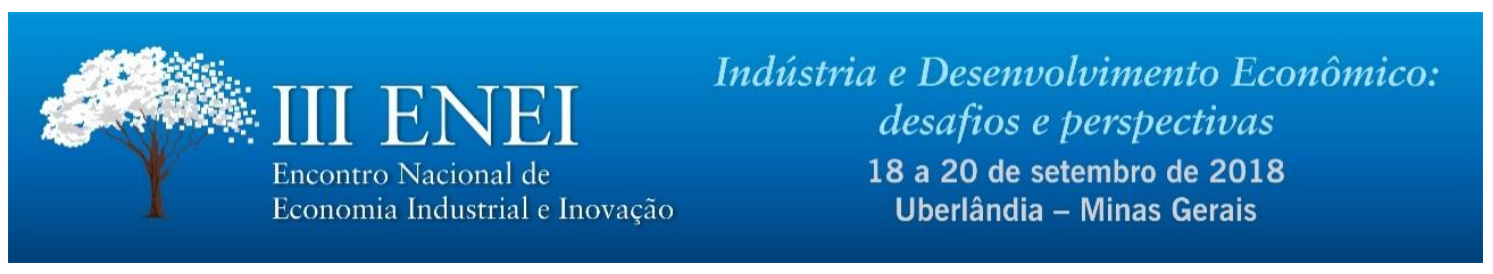

\title{
ANÁLISE DA POLÍTICA DE EXPANSÃO DO ENSINO SUPERIOR E TÉCNICO NO BRASIL E SUAS REPERCUSSÕES NO SISTEMA INOVATIVO DO RIO GRANDE DO SUL
}

Iago Luiz da Silva ${ }^{1}$

Ana Lúcia Tatsch ${ }^{2}$

\section{Resumo}

O objetivo do trabalho foi o de verificar se a recente interiorização das instituições de ensino superior e técnico tem contribuído para o fortalecimento do sistema inovativo do Rio Grande do Sul, baseado na hipótese de que, através da política, está havendo uma maior qualificação da infraestrutura técnicacientífica e intensificação das relações entre os agentes do estado. São utilizados dados do MEC, GEOCAPES e DGP/CNPq, atinentes à evolução dos cursos de graduação, dos programas de pósgraduação, dos grupos de pesquisa e de suas interações com as demais organizações. Observou-se que os cursos criados no estado, após 2003, estão contribuindo para uma desconcentração da oferta do ensino superior e técnico, em concordância com as atividades características de sua localidade ou atuando no sentido de suscitar o desenvolvimento de setores não tradicionais. Além disso, está havendo um processo de desconcentração geográfica dos programas de pós-graduação, estimulando uma maior qualificação e profissionalização de recursos humanos em diversas partes do estado. Os grupos de pesquisa em maior número e com pesquisadores com maior grau de formação estão se relacionando mais com outras organizações e com parcerias de longo prazo. Assim, a combinação desses movimentos está contribuindo para o fortalecimento do sistema inovativo gaúcho.

Palavras-chaves: expansão do ensino superior e técnico, universidade, sistema inovativo, Rio Grande do Sul

Área ABEIN:Área 4 - Redes e sistemas urbanos, regionais e nacionais; Subárea: Redes de inovação aliança de $\mathrm{P} \& \mathrm{D}$, interações universidade-empresa, outras redes.

JEL: O3, O15, R1.

\section{Introdução}

O papel da universidade como agente integrador de um sistema inovativo pode assumir duas características principais: a de instituição formadora de profissionais (cientistas, engenheiros e pesquisadores) e locus de desenvolvimento de pesquisa com a competência de difundir o conhecimento gerado em seu interior (NELSON, 1992; PORTER; STEM, 2001). A característica de formadora de recursos humanos é importante, de'ntro outros motivos, na medida em que aumenta a base de profissionais tecnicamente treinados (MOWERY; ROSENBERG, 1989; PAVITT, 1998; LUNDVALL, 2002; VELHO, 2007), que desenvolvem as habilidades de entender, padronizar e localizar informações para a resolução de problemas no contexto da ciência básica (SALTER et. al, 2000). Como locus de desenvolvimento de

\footnotetext{
${ }^{1}$ Doutorando em Economia do Desenvolvimento pelo Programa de Pós-graduação em Economia da Universidade Federal do Rio Grande do SUL (PPGE/UFRGS).

${ }^{2}$ Professora adjunta do Departamento de Economia e Relações Internacionais da Universidade Federal do Rio Grande do Sul (UFRGS).
} 
pesquisa, a universidade também é importante, uma vez que possui uma cultura de avanço e disseminação pública do conhecimento (DOTRIAUX, 2008), além de uma capacidade para o acumulo e transmissão de conhecimento (PIRNAY et al., 2003; LIND; STYHRE; AABOEN, 2013)

Os estudos das relações entre universidade e empresa (U-E) surgem no contexto da inovação como resultado de um processo interativo entre os demais agentes de um sistema. Essa literatura investiga a intensidade da relação entre universidade e empresa do ponto de vista geográfico e setorial; e busca compreender suas as características, analisando os tipos de colaboração, os termos econômicos dos acordos e as áreas científicas estudadas (BONNACORSI; PICCALUGA, 1994).

No Brasil, entre 1950 e 1970, a universidade cumpriu o papel de treinar recursos humanos para fomentar o processo de industrialização De 1970 a 1990, com uma diversificação da base industrial, a universidade, além de formar recursos humanos especializados, passa também a desenvolver as funções de formação de pesquisadores para o processo de aprendizado (DE MELLO; MACULAN; RENAULT, 2011). Mais recentemente, entre 2003 e 2014, foi implementado uma política de expansão do ensino superior e técnico, que se configurou como um marco na história das universidades e centros de formação ao viabilizar maior disponibilidade de vagas. Calcou-se fundamentalmente na expansão e interiorização das universidades e institutos federais. Nesse período, foram criadas 18 novas universidades federais $(+46,5 \%)$; 173 novos câmpus (+117\%), sendo a maioria no interior do País; 2.820 novos cursos de graduação presencial $(+138 \%) ; 122.650$ novas vagas em graduação presencial $(+108,3 \%)$ e 154.792 novas matrículas em pós-graduação (+316\%). O orçamento total do Ministério da Educação (MEC) saiu de 33,9 R \$ bilhões ${ }^{3}$ em 2003 para 101,9 R \$ bilhões em 2014 (+201\%) (BRASIL, 2015).

A institucionalidade das universidades também foi modificada com a implantação do Sistema de Seleção Unificada (Sisu), do Programa Nacional de Assistência Estudantil (Pnaes), do Programa Bolsa Permanência (PBP), da Lei de Cotas, e da maior flexibilidade e interdisciplinaridade às instituições, entre outros aspectos (BRASIL, 2015). Outra frente de atuação da política foi a criação dos Institutos Federais de Educação, Ciência e Tecnologia (IFs). De 1909 até 2002, existiam no Brasil 140 escolas dedicadas ao ensino técnico, e, entre 2003 e 2016, foram criados mais de 500 câmpus (BRASIL, 2016). Essa ação foi viabilizada através da integração das antigas Escolas Agrotécnicas Federais (EAFs), Escolas Técnicas (ETs) e Escolas Vinculadas às Universidades Federais (EVs) e da criação de mais 38 novos IFs, com atuação em todas as unidades federativas do País.

A política de expansão do ensino superior e técnico partiu do entendimento que a universidade é capaz de exercer papel importante na estrutura produtiva local. Logo, tal ampliação buscou se atrelar à "vocação da região", através da implantação de novos cursos relacionados ao perfil produtivo dos municípios. Segundo os relatórios da política, os câmpus foram "preferencialmente implantados, em municípios, respeitando a vocação regional e atendendo ao plano estratégico para o desenvolvimento do País" (BRASIL, 2015, p.36). No desenho da política, o governo estabeleceu que seu principal objetivo seria o desenvolvimento regional e, para tanto, aumentar e aprimorar os recursos humanos das regiões do País fazia-se necessário. Assim, com o aumento do número e da qualidade das universidades, o governo poderia oferecer bases sólidas para a consecução de seus objetivos.

Tal movimento de expansão do ensino superior e técnico é verificado com maior intensidade no Rio Grande do Sul, se comparado com outras unidades federativas. Foram criadas 3 novas universidades e foi o estado que mais recebeu novos câmpus, 20 no total, representando $11,6 \%$ dos 173 construídos em todo o País. Além disso, passou a sediar 3 IFs: IFSul, IFRS e IFFarroupilha, com mais de 35 câmpus espalhados pelo estado.

Diante da relevância desta política e de sua importância para o RS, este trabalho busca responder a seguinte pergunta de pesquisa: A recente expansão e interiorização das instituições de ensino superior e técnico tem contribuído para o fortalecimento do sistema inovativo do Rio Grande do Sul? A hipótese do trabalho é que a política, promovida pelo governo federal, ao aumentar o número de universidades em direção ao interior do País, contribuiu para que a maior qualificação da infraestrutura técnica-científica e a

\footnotetext{
${ }^{3}$ Valor constante.
} 
intensificação das relações entre os agentes (Estado, universidade e empresa) fortalecesse o sistema inovativo gaúcho. Dessa forma, visa-se analisar a implementação da política de expansão e interiorização do ensino superior e técnico no Rio Grande do Sul, e sua contribuição para o fortalecimento do Sistema Inovativo do estado.

O trabalho está dividido em outras quatro seções, além desta introdução. Na seção 2, apresentamse os procedimentos metodológicos utilizados, bem como os dados e suas fontes. Na seção 3, é apresentada a política de expansão do ensino superior de forma geral no Brasil e mais detalhadamente no Rio Grande do Sul. Na seção 4 são apresentados os resultados encontrados a partir da metodologia utilizada. Por fim, são feitas as considerações finais. 3

\section{Procedimentos Metodológicos}

Os dados utilizados no presente trabalho foram retirados de fontes secundárias. As fontes dos dados utilizados foram o e-MEC, o Sistema de Georreferenciamento da Coordenação de Aperfeiçoamento de Pessoal de Nível Superior (GEOCAPES), o Diretório dos Grupos de Pesquisa do Conselho Nacional de Desenvolvimento Científico e Tecnológico (DGP/CNPq) e o IBGE. Os dados do e-MEC, do Ministério da Educação, foram utilizados em um primeiro momento para a análise do comportamento dos cursos de graduação no RS. O e-MEC é uma base de dados oficial relativa às Instituições de Educação Superior e seus cursos de graduação. Na busca textual foram colhidas informações dos cursos de graduação, como: a instituição, o curso, a modalidade (se bacharelado, licenciatura ou tecnológico), a data de criação e o câmpus em que o curso está lotado. Os cursos foram classificados segundo seu ano de criação, separandoos em dois grupos: antes de 2003, para todos os cursos criados antes do período de implementação da política; e após 2003, para todos os cursos criados no bojo da política. A partir dessas informações, os cursos foram caracterizados segundo a sua grande área ${ }^{4}$, modalidade e classificados segundo a microrregião em que eram ofertados. Além disso, foram pesquisados os sites dos institutos federais e universidades para contextualização da criação e desenvolvimento das instituições de ensino superior e técnico.

Além de dados que apresentam a expansão dos cursos de graduação, foram pesquisados dados relativos à evolução do número de programas de pós-graduação no RS, bem como suas grandes áreas. Compreender a dinâmica dos números da pós-graduação é de suma importância. Isso porque a maioria das interações entre universidade, empresa e outras organizações se dá via grupos de pesquisas, que, por sua vez, estão vinculados aos programas de pós-graduação. Dessa forma, os dados foram extraídos da base de dados do GEOCAPES, filtrados conforme as instituições selecionadas, classificados segundo a grande área ${ }^{5}$ e a microrregião em que situam e tabulados de forma a capturar a realidade no momento anterior à implementação da política e a conjuntura mais atual.

Como proxy da interação U-E, foram considerados os grupos de pesquisa e seus relacionamentos com outras instituições. Os dados relativos aos grupos de pesquisa foram extraídos da base de dados do DGP/CNPq, e apresentam uma fotografia bianual dos recursos humanos que formam os grupos de pesquisa (número e formação de pesquisadores, estudantes e técnicos); das linhas de pesquisas em andamento; das especialidades do conhecimento; dos setores de aplicação envolvidos; da produção científica, tecnológica e artística (número de patentes, livros, revistas e artigos publicados); e das interações entre os grupos de pesquisa com empresas e demais instituições ${ }^{6}$ (CNPq/DGP, 2017). Os dados do DGP/CNPq foram analisados com o objetivo de mapear a interação entre os grupos de pesquisa e demais organizações.

\footnotetext{
${ }^{4}$ Essa caracterização foi feita a partir da categorização estabelecida no Censo do Ensino Superior do MEC.

5 A classificação das grandes áreas dos programas de pós-graduação do GEOCAPES é distinta da classificação das grandes áreas dos cursos de graduação do e-Mec.

““[a] existência da atividade permanente de pesquisa numa instituição é condição prévia para participação dela no DGP, e não o contrário. Em outras palavras, o início de processo de criação ou implantação de atividades de pesquisa em uma instituição não se dá pelo Diretório" (CNPq/DGP, 2017).
} 
A base de dados do Diretório é composta pelos censos dos anos de 1993, 1995, 1997, 2000, 2002, 2004, 2006, 2008, 2010, 2014 e 2016. Em 2016, 531 instituições no Brasil participaram do Censo, registrando 37.640 (2.325) grupos de pesquisa, com 129.929 pesquisadores, professores e técnicos doutores. Optou-se por utilizar os dados dos Censos de 2002 a 2016 porque, além de captar o momento anterior de implementação da política de expansão e, depois, toda sua execução, a comparação com os censos da década de 1990 não é muito apropriada. Isso porque a construção desses censos possui problemas de coleta de informações e baixo alcance (CNPq/DGP, 2017).

Para uma análise qualitativa dos dados dos grupos de pesquisa, foram pesquisadas as atividades econômicas de cada empresa ou instituição com relacionamento com as universidades e institutos federais analisados e, de acordo com a Classificação Nacional de Atividades Econômicas (CNAE), as instituições parceiras foram categorizadas segundo o setor (primário, secundário ou terciário), a seção (agricultura, pecuária, indústria de transformação, indústria extrativa, serviços de educação, serviços de informação e comunicação etc.) e, em alguns casos, as divisões dentro das seções.

Para melhor captar as nuances da política no estado, utilizou-se a divisão feita pelo IBGE em nível da microrregião ${ }^{78}$. O software utilizado para visualização espacial dos dados foi o GeoDa.

\section{A política de expansão}

\subsection{A política de expansão do ensino superior e técnico no Brasil}

O processo de expansão da educação superior no Brasil foi uma construção de uma série de governos. Baseada fundamentalmente na Constituição de 1988, apoiou-se no Plano Nacional de Educação - PNE $(2001-2010)^{9}$ que, por sua vez, fundamentou-se na Lei de Diretrizes Básicas - LDB ${ }^{10}$. O Plano destacou o importante papel que as universidades públicas desempenham na pesquisa básica, na pósgraduação stricto sensu, no ensino de graduação e na formação de docentes tanto da educação básica quanto da educação superior, objetivos e metas traçadas na LDB. As diretrizes do Plano se baseiam na noção de que o conhecimento é um grande elemento dinamizador das sociedades e que, por essa razão, deve ser dada uma maior atenção às IES. (BRASIL, 2001). O Plano preocupa-se em determinar, de forma geral, a necessidade de revisão e ampliação do apoio à pós-graduação e à pesquisa científica, tecnológica e humanística nas universidades (BRASIL, 2001).

Desse modo, a partir de 2005, é verificado um ponto de inflexão nas ações voltadas a apoiar a educação superior pública. Isso porque, entre 1995 e 2004, foram criadas seis universidades federais ${ }^{11}$; ao passo que, de 2005 a 2014, foram construídas 18, abrangendo todas as regiões do País, com 173 novos câmpus e 2.820 novos cursos de graduação. Dentro do período da política podem identificadas três fases que buscaram o objetivo de expansão das vagas através de formas distintas: a Fase I (2003-2007), a Fase II (2008-2012) e a Fase III (2012-2014).

\footnotetext{
${ }^{7}$ No final de 2017, o IBGE revisou o método de divisão do território brasileiro e passou a adotar as Regiões Geográficas Intermediárias e Regiões Geográficas Imediatas como substitutos das unidades mesorregionais e microrregionais, respectivamente. Contudo, a transição para a nova classificação, com a disponibilização de novos dados estatísticos, está planejada para durar dez anos (IBGE, 2018).

${ }^{8}$ No Apêndice A consta o mapa da divisão do Rio Grande do Sul por microrregiões. Ele tem a função de apoiar a leitura da análise das seções a seguir.

${ }^{9}$ Lei ${ }^{\circ} 10.172 / 2001$.

${ }^{10}$ Lei n n $^{9} .394$ de 20 de dezembro de 1996.

11 As seis universidades criadas foram as seguintes: Universidade Federal do Tocantins (UFT) - Lei $\mathrm{n}^{\mathrm{o}} 10.032$ de 2000 ; Universidade Federal de Campina Grande (UFCG) - Lei n ${ }^{\circ} 10.419$ de 2002; Universidade Federal de São João del-Rei - Lei ${ }^{\circ}$ 10.425 de 2002; Universidade Federal de Itajubá (UNIFEI) - Lei n ${ }^{\circ} 10.435$ de 2002; Universidade Federal do Vale do São Francisco (UFVASF) - Lei n ${ }^{\circ} 10.473$ de 2002; Universidade Federal Rural da Amazônia (UFAM) - Lei nº 10.611 de 2002.
} 
A Fase I teve como objetivo principal a interiorização e a descentralização do ensino público (BRASIL, 2015). Para tanto, foram criadas 10 novas universidades ${ }^{12}$ e 79 câmpus em todas as regiões do País. Do total de câmpus criados, a maioria (48) foi construída em municípios com menos 100 mil habitantes. Apesar disso, a política continuou privilegiando a região litorânea brasileira, que historicamente concentra parte considerável do total da população ${ }^{13}$. Assim, na primeira Fase, a política se limitou a construir novos câmpus, sem um planejamento mais detalhado de suas metas e ações. Um possível motivo para essa forma de agir pode ser o restrito raio de ação que a política econômica impunha no período ${ }^{14}$. No entanto, esse quadro se altera a partir de 2008.

A Fase II pode ser considerada a mais importante para a política de expansão, não só pelo volume de recursos transferidos às instituições, mas especialmente pelos resultados alcançados. Diferentemente da primeira, a Fase II calcou-se na expansão e reestruturação das universidades federais através do Reuni ${ }^{15}$, Programa de Apoio a Planos de Restruturação e Expansão das Universidades Federais ${ }^{16}$. As quatro novas universidades ${ }^{17}$ desse período foram criadas com objetivos ligados ao desenvolvimento regional e à internacionalização (BRASIL, 2015).

Mesmo que a criação de novos câmpus tenha sido feita em um ritmo menor que no período anterior, a Fase II continuou com o objetivo de interiorização e desconcentração regional da oferta de vagas. Há uma forte tendência de expansão para o interior das regiões Norte, Nordeste e Sul, sendo Minas Gerais e Rio Grande do Sul os estados mais privilegiados com novos câmpus nessa fase. Além da criação do plano de restruturação das universidades federais, é nesse período que se institui a Rede Federal de Educação Profissional, Científica e Tecnológica18. Em 2015, existiam 40 IFs no Brasil, ofertando mais de 55 mil vagas em seus cursos. Desse total, $34,1 \%$ das vagas são ofertadas na região Nordeste e 30,8\% na região Sudeste. O Cento-Oeste e o Sul possuem juntos cerca de $15 \%$ das vagas ofertadas. Apesar da região Norte não ser a que menos tem IFs, é a que menos oferta vagas, com 3.220, correspondendo a 5,8\% do total.

Em síntese, a Fase II da política de expansão do ensino superior criou importantes novas universidades, um grande número de câmpus (a maioria no interior pouco desenvolvido do Brasil). Além disso, constituiu uma importante Rede de ensino técnico baseado no conhecimento tecnológico, e que atende um grande número de municípios no Brasil.

\footnotetext{
${ }^{12}$ Universidade Federal de Alfenas (UNIFAL) - Lei n ${ }^{\circ} 11.154$ de 29/07/2005, Universidade Federal dos Vales Jequitinhonha e Mucuri (UFVJM) - Lei no 11.173 de 06/09/2005, Universidade Federal do Triângulo Mineiro (UFTM) - Lei $n^{\circ} 11.152$ de 29/07/2005, Universidade Federal do Semi-árido (UFERSA) - Lei no 11.155 de 29/07/2005, Universidade Tecnológica Federal do Paraná (UTFPR) - Lei no 11.184 de 07/01/2005, Fundação Universidade Federal do ABC (UFABC) - Lei $\mathrm{n}^{\circ} 11.145$ de 26/07/2005, Fundação Universidade Federal de Grande Dourados (UFGD) - Lei no 11.153 de 29/07/2005, Universidade Federal do Recôncavo Baiano (UFRB) - Lei no 11.151 de 29/07/2005, Fundação Universidade Federal de Ciências da Saúde de Porto Alegre (UFCSPA) - Lei nº 11.641 de 11/01/2008, e Fundação Universidade Federal do Pampa (Unipampa) - Lei nº 11.640 de 11/01/2008.

${ }^{13}$ Para melhor compreender a evolução das características territoriais e demográficas brasileiras ver Diniz (2013).

${ }^{14}$ Inicialmente, com uma política macroeconômica ortodoxa, o Primeiro Governo Lula administrava as tensões das forças internas que apoiavam uma menor participação do Estado e daquelas que defendiam a realização da Constituição Cidadã. Em um segundo momento, no Segundo Governo Lula, fatores internos e externos propiciaram uma retomada das políticas sociais (FAGNANI, 2011).

15 Decreto n 6.096.

${ }^{16}$ Para aderir ao Programa, cabia às IFES a apresentação ao MEC de um plano de reestruturação alinhado aos objetivos e diretrizes estabelecidos pelo Ministério, indicando a estratégia e as etapas a serem concluídas, além de uma estimativa dos recursos necessários para sua execução.

${ }^{17}$ Universidade Federal da Fronteira Sul (UFFS) - Lei no 11.029 de 15/09/2009, Universidade Federal do Oeste do Pará (UFOPA) - Lei ${ }^{\circ} 12.085$ de 05/11/2009, Universidade Federal da Integração Latino-americana (UNILA) - Lei $\mathrm{n}^{\circ} 12.189$ de 12/01/2010, Universidade da Integração Internacional da Lusofonia Afro-Brasileira (UNILAB) - Lei nº 12.289 de 20/07/2010.

${ }^{18}$ Com diretrizes traçadas pelo Decreto nº.095 de 2007 e Lei no 11.892 de 2009.
} 
Para além das 4 novas universidades ${ }^{19}$ criadas na Fase III e dos 47 novos câmpus, nesse período, a política priorizou o desenvolvimento de um arranjo institucional que fortalecesse os investimentos feitos nos anos anteriores. Entre 2012 e 2014, portanto, é criada a seguinte institucionalidade: Lei de $\operatorname{Cotas}^{20}$, Programa Bolsa Permanência (PBP) ${ }^{21}$, Programa Idioma Sem Fronteiras (IsF), Programa de Estímulo à Reestruturação e ao Fortalecimento das Instituições de Ensino Superior (Proies) e Política Nacional de Expansão das Escolas Médicas das Instituições Federais de Educação Superior.

Na Fase III, percebe-se o quanto as regiões Norte e Nordeste foram privilegiadas em detrimento do Sul, Sudeste e Centro Oeste. Na região Nordeste, a Bahia foi o estado mais beneficiado, com duas novas universidades e 9 novos câmpus presentes em quase todas as mesorregiões do estado. O Ceará foi o segundo que mais recebeu novos câmpus, com 5 novas unidades, ligadas principalmente à nova Universidade, a UFCA.

Dessa forma, a expansão das novas universidades e dos novos câmpus é condizente com o objetivo inicialmente estabelecido: o de interiorização e de ligação dessas universidades com o desenvolvimento regional. Essa característica é percebida principalmente nas duas primeiras fases, com universidades criadas para atender esse tipo de objetivo. Ao todo, 168 municípios receberam ao menos uma nova unidade ligada a uma universidade ${ }^{22}$. Ao todo, 111 municípios com menos de 100 mil habitantes receberam novas unidades, correspondendo a $65,5 \%$ de todas as unidades construídas. A maior capilaridade das instituições de ensino superior e técnico pode contribuir para uma melhor qualificação dos recursos humanos em regiões distantes das capitais, que historicamente concentravam a oferta de cursos superiores da rede federal. A Figura 1, apresenta a distribuição geográfica do número de câmpus antes e depois da política.

\section{Figura 1 - Distribuição geográfica do número de câmpus antes e depois da política de expansão do ensino superior e técnico}

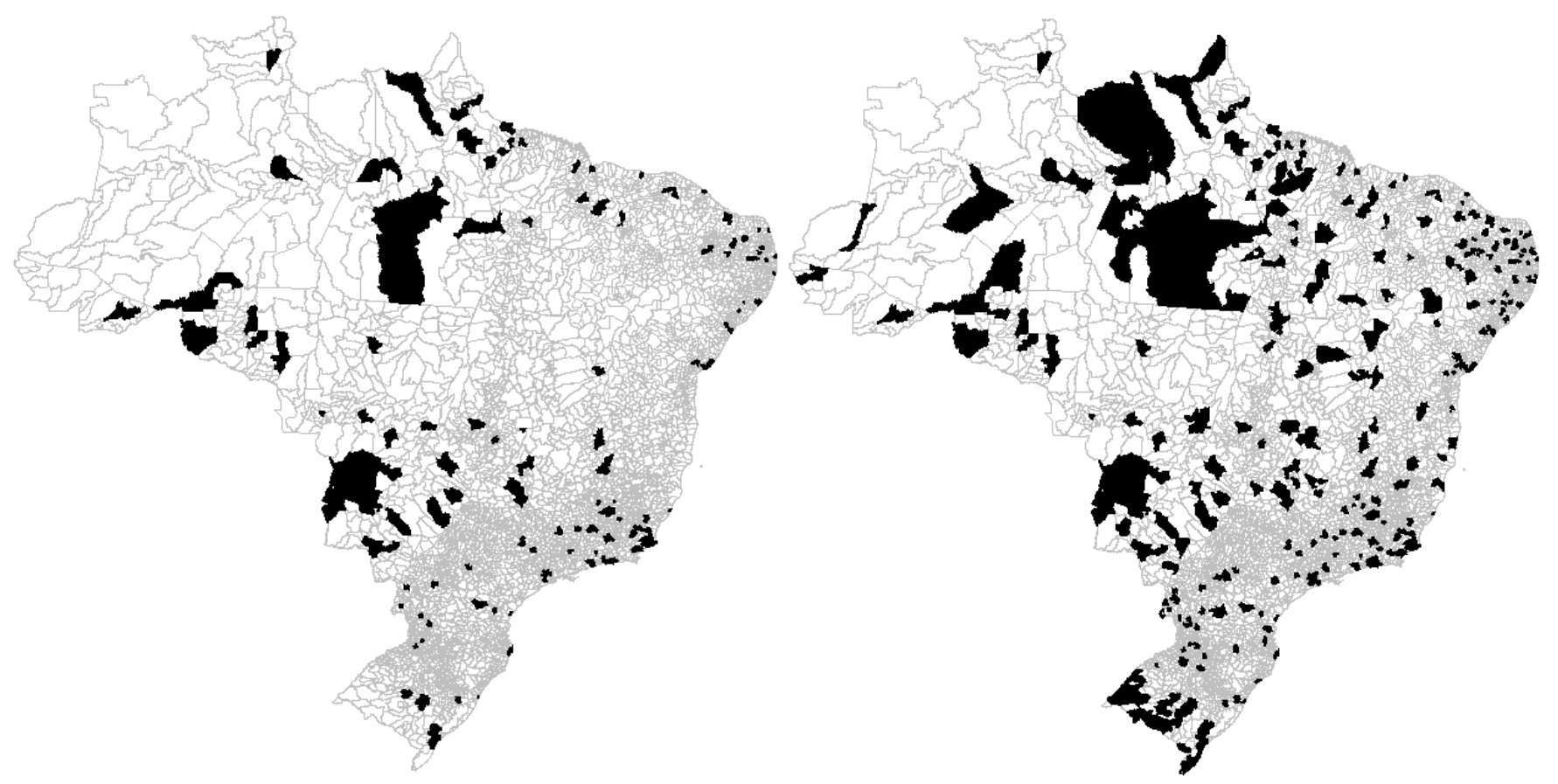

Fonte: Brasil (2015).

\footnotetext{
${ }^{19}$ Universidade Federal do Oeste da Bahia (UFOB) - Lei no 12.825 de 05/06/2013, Universidade Federal do Sul da Bahia (UFESBA) - Lei no 12.818 de 05/06/2013, Universidade Federal do Sul Sudeste do Pará (UNIFESSPA) - Lei n 12.824 de 05/06/2013, Universidade Federal do Cariri (UFCA) - Lei no 12.826 de 05/06/2013.

${ }^{20}$ Lei n $^{\mathrm{o}} 12.711$ de 2012, regulamentada pelo Decreto $\mathrm{n}^{\mathrm{o}} 7.824$ de 2012.

${ }^{21}$ Decreto $n^{\circ} 7.416$ de 2010.

${ }^{22}$ Desse conjunto, 4 municípios receberam mais de um novo câmpus: Brasília (DF), Diadema (SP), Macaíba (RN) e Petrolina (PE).
} 
O crescimento no número de câmpus é o instrumento pelo qual buscou-se o objetivo principal: aumentar a disponibilidade de vagas no ensino superior. Apesar de uma desconcentração no número de câmpus em direção às regiões Norte e Nordeste, houve um agravamento da concentração do número de vagas e matrículas no Sul e Sudeste. Enquanto em 2002 a região Norte ofertava 14,8\% do total de vagas, em 2013 essa participação diminui para 8,5\%. Esse movimento se deu em detrimento de uma maior participação do Sul, Sudeste e Nordeste. Apesar disso, o crescimento no número de oferta de vagas é superior a $100 \%$ na maioria das regiões. Apenas na região Norte que esse crescimento gira em torno de 20\%. A Tabela 1 sintetiza dados relativos à expansão dos câmpus, vagas e matrículas por região.

Tabela 1 - Expansão de indicadores acadêmicos na educação superior - por região

\begin{tabular}{|c|c|c|c|c|c|c|c|c|c|}
\hline \multirow{2}{*}{ Região } & \multicolumn{3}{|c|}{ Câmpus } & \multicolumn{2}{|c|}{ Vagas } & \multicolumn{4}{|c|}{ Matrículas } \\
\hline & 2002 & 2014 & $\Delta \%$ & 2002 & 2013 & $\Delta \%$ & 2002 & 2013 & $\Delta \%$ \\
\hline Norte & 24 & 56 & 133 & 16.775 & 20.094 & 20 & 76.779 & 128.228 & 67 \\
\hline Nordeste & 30 & 90 & 200 & 33.587 & 75.052 & 123 & 147.464 & 281.241 & 91 \\
\hline Sul & 29 & 63 & 117 & 17.152 & 42.241 & 146 & 75.985 & 157.206 & 107 \\
\hline Sudeste & 46 & 81 & 76 & 32.509 & 71.502 & 120 & 139.641 & 275.687 & 97 \\
\hline $\begin{array}{l}\text { Centro } \\
\text { Oeste }\end{array}$ & 19 & 31 & 63 & 13.260 & 27.044 & 104 & 60.590 & 89.721 & 48 \\
\hline Brasil & 148 & 321 & 117 & 113.283 & 235.933 & 108 & 500.459 & 932.083 & 46 \\
\hline
\end{tabular}

Fonte: CENSO/INEP em Brasil (2015).

Segundo o Censo do Ensino Superior do MEC, em 2001, dentre universidades e instituições de ensino técnico, 40 se localizavam em capitais do Brasil e somente 16 no interior. Com o fim da política, 61 se localizavam nas capitais e 42 no interior. Ou seja, o crescimento no número de IFES se deu predominantemente em direção ao interior. Enquanto o crescimento do número de universidades nas capitais foi de $15 \%$, com a construção de 4 novas instituições, aquelas construídas no interior apresentaram crescimento de 167\%, com a instalação de 20 novas universidades. Em 2014, pela primeira vez, o número de universidades sediadas no interior foi superior ao das capitais. Esse movimento foi essencial para a desconcentração da formação de recursos humanos das capitais em direção a municípios menores.

$\mathrm{Na}$ esfera dos recursos humanos, há um importante crescimento no número de docentes entre 2001 e 2015, principalmente a partir de 2008 quando os planos de reestruturação das universidades federais começam a ser executados e a Rede técnica é instituída. O número total de docentes passa de $51.756 \mathrm{em}$ 2001 para 111.086 em 2015. Para além do substancial crescimento do número de docentes em IFES no período, da ordem de 115\%, há uma melhora no nível de formação dos professores. Em 2001, o quadro de docentes era composto da seguinte forma: 15,5\% eram apenas graduados, 15,9\% especialistas, 33,3\% mestres, 35,2\% doutores e 0,1\% sem graduação. Em 2015, do total de 111.086 professores, 4,3\% eram graduados, $6,4 \%$ especialistas, $28,2 \%$ mestres e $61,1 \%$ doutores e $0,01 \%$ sem graduação.

De 2001 a 2016, o número de programas de pós-graduação no Brasil cresceu 169\%. Os programas que ofertavam tanto mestrado quanto doutorado cresceram $139 \%$ no período. Em 2001, representavam $57 \%$ do total dos programas de pós-graduação, e, em 2016, caiu para 50\%. Do mesmo modo, os programas que ofereciam mestrado cresceram em números absolutos entre o período de análise, mas perderam participação ao longo do tempo, de 36\%, em 2001, para $31 \%$ em 2016. Em contrapartida, houve um expressivo 
crescimento dos programas de pós-graduação que ofertam apenas mestrado profissional no Brasil $(+2.324 \%)$, ganhando espaço entre os demais programas ${ }^{23}$.

Como visto, a estrutura do ensino superior federal apresentou uma importante evolução entre 2003 e 2014, com a desconcentração no número de câmpus da região Sudeste para a Norte e Nordeste, e da capital para o interior. No entanto, há também um crescimento da concentração do número de vagas nas regiões Sul e Sudeste. Há uma melhora na formação do quadro docente das universidades e institutos federais, com uma relação maior de professores doutores. Além disso, na busca de uma melhor racionalização da estrutura física, diversificou a oferta de ensino, incentivando a criação de cursos noturnos. A política estimulou o desenvolvimento e consolidação da pós-graduação e da pesquisa das universidades.

\subsection{A política de expansão do ensino superior e técnico no $R S$}

O Rio Grande do Sul foi o estado que mais recebeu novos câmpus em todo o período da política de expansão, foram 20 no total, sendo 11 na Fase I, 7 na Fase II e 2 da Fase III. Além disso, três novas universidades foram criadas, bem como três novos Institutos Federais com seus câmpus espalhados por toda a extensão territorial do estado. Antes disso, o estado contava com uma oferta de cursos de ensino superior público concentrada nos grandes municípios do estado; o mesmo ocorria com a oferta de programas de pós-graduação e, por consequência, dos grupos de pesquisa.

O estado, até 2003, contava com 4 universidades federais, que restringiam sua atuação nas cidades que as sediavam (excetuando-se a UFPel que tinha câmpus também em Capão do Leão). A partir da implementação da política de expansão passa a contar com 20 novos câmpus. Aumenta-se assim a rede federal de ensino superior no Rio Grande do Sul.

Visualizando a disposição dos cursos pelo território do estado do Rio Grande do Sul é possível compreender a dimensão da política implementada. A Figura 2, a seguir, apresenta o número de cursos por microrregião do estado antes e após a política. Antes de 2003, os cursos, tanto de ensino superior quanto técnico, eram ofertados nas microrregiões de Porto Alegre, sendo 63 cursos na capital, com a UFRGS e em Sapucaia do Sul, através do antigo CEFET/RS; de Pelotas, com 49 cursos na cidade homônima e em Capão do Leão com a UFPel; de Santa Maria, disponibilizando 44 cursos no município que dá nome à microrregião com a UFSM; e do Litoral Lagunar, ofertando 31 cursos no município de Rio Grande com a FURG.

\section{Figura 2 - Cursos de graduação total no RS por microrregião antes e após a política}
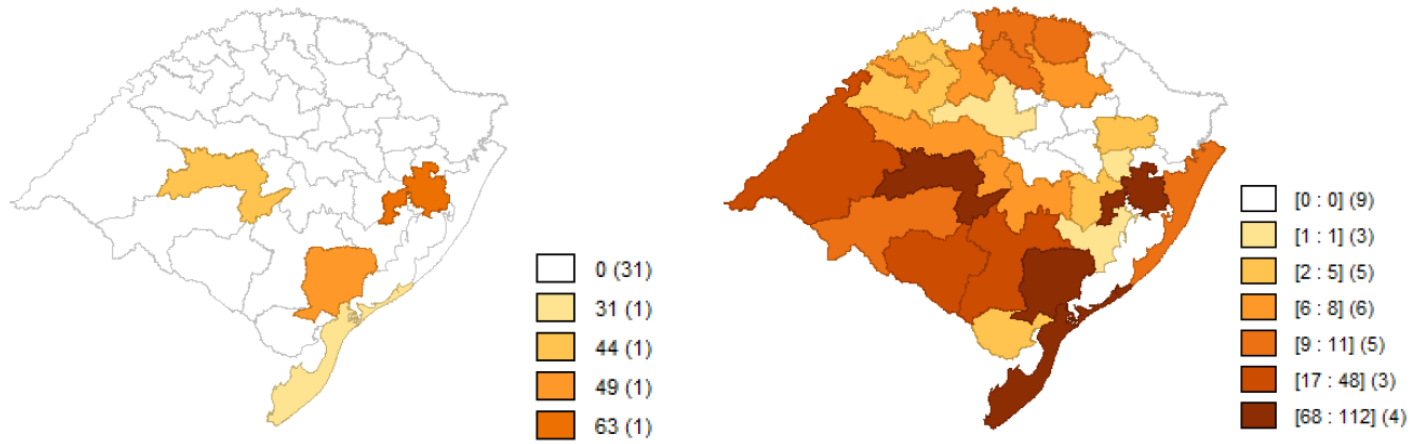

Fonte: Elaboração própria com base em MEC (2017).

*Os valores entre colchetes indicam os intervalos do número de cursos.

**Os valores entre parênteses indicam o número de microrregiões com a respectiva quantidade de cursos.

Após a implementação da política, o estado passa a contar com câmpus em quase todo seu território Apenas 9 das 35 microrregiões do Rio Grande do Sul atualmente não sediam câmpus e, portanto, não

\footnotetext{
${ }^{23}$ Além disso, do ponto de vista institucional, a política introduziu avanços no estabelecimento de diretrizes curriculares flexíveis nas universidades recém-criadas e avançando em mecanismos que incentivassem o acesso da população marginalizada, com políticas de cotas e permanência.
} 
ofertam cursos de ensino superior ou técnico presencial, são elas: Três Passos, Sananduva, Não-me-toque, Soledade, Guaporé, Vacaria, Santa Cruz do Sul, Lajeado-Estrela e Gramado-Canela, a maioria na porção Norte-Nordeste do estado, justamente a que apresenta maior renda per capita. Este é um primeiro indício de que a política se orientou por não reforçar a divisão Norte-Sul existentes na estrutura produtiva do estado, com um Norte dinâmico e um Sul deprimido

As universidades mais tradicionais do estado se aproveitaram do momento positivo para as instituições de ensino superior e aumentaram de forma considerável o número de seus cursos. A UFSM criou 62 novos cursos, dos quais apenas um ainda não iniciou suas atividades. A UFPel criou 60 novos cursos, dos quais 5 ainda não iniciaram suas atividades. A UFRGS criou 29 novos cursos, sendo 4 ainda sem início de suas atividades. Já a FURG criou 28 novos cursos, dos quais a maioria em 2009, sendo um ainda não iniciado (Multidisciplinar em dependência química). O importante crescimento do número de cursos criados nas instituições tradicionais pode ser justificado pela prévia existência de uma infraestrutura física e de recursos humanos.

O ensino técnico federal do Rio Grande do Sul antes de 2003 era ofertado por 5 instituições: os Centros Federais de Educação Tecnológica de Bento Gonçalves, de Pelotas e de São Vicente do Sul; as Escolas Agrotécnicas de Alegrete e de Sertão; e a Escola Técnica Federal de Canoas.

Dos 187 cursos de ensino superior e técnico ofertados no Rio Grande do Sul antes de 2003, 129 eram bacharelados, 52 licenciaturas e 6 tecnológicos. Esses últimos ofertados em sua totalidade nos antigos CEFETs. Dos cursos de bacharelados, a maioria pertencia à grande área de Ciências Sociais, Negócios e Direito, 33 ao todo. Engenharia, Produção e Construção é a segunda maior grande área no estado, com 30 cursos, esses concentrados na capital. A área de Saúde e Bem-estar social, que integra cursos como Medicina, Enfermagem, Educação Física e Nutrição, tinha 23 cursos associados. Dos 8 cursos ligados à Agricultura e Veterinária, área com menos cursos no estado, 3 estavam sediados em Santa Maria, 2 em Pelotas e 2 em Porto Alegre.

A política de expansão do ensino superior e médio começa a se concretizar no Rio Grande do Sul a partir de 2005, quando da criação de duas novas universidades: a Fundação Universidade Federal de Ciências da Saúde de Porto Alegre (UFCSPA) e a Fundação Universidade Federal do Pampa (Unipampa). $\mathrm{Na}$ Fase I da política, 11 municípios foram beneficiados, dos quais 10 receberam novos câmpus da recémcriada Unipampa. A maioria das novas unidades universitárias foram criadas na região de campanha do estado: 2 na Campanha Central, 2 na Campanha Meridional e 4 na Campanha Ocidental. O outro câmpus criado está ligado à UFSM e foi instalado no município de Palmeira das Missões, na microrregião de Carazinho.

Na Fase II o estado foi beneficiado com 7 novos câmpus e uma nova universidade: a Universidade Federal da Fronteira Sul (UFFS), que atua tanto no Rio Grande do Sul como no Paraná e em Santa Catarina, com o objetivo de integração dos estados da região Sul. Dos 7 novos câmpus, 3 foram para a FURG (Santa Vitória do Palmar, Santo Antônio da Patrulha e São Lourenço do Sul); 2 para a UFFS (Cerro Largo e Erechim), 1 para a UFPel (Pelotas) e 1 para a UFSM (Silveira Martins). Os maiores municípios que receberam novas unidades universitárias nessa fase são Erechim e Pelotas, com 101 mil e 341 mil habitantes, respectivamente. Os demais possuem menos de 50 mil habitantes.

Na fase III, que, de modo geral, criou menos câmpus vis-à-vis as outras fases, o estado recebeu duas novas unidades: uma em Passo Fundo, ligada à UFFS, e outra em Tramandaí, na microrregião de Osório, região litorânea do estado, esta ligada à UFRGS.

Para além da criação de novas universidades e novos câmpus a elas ligados, o estado também se beneficiou da criação dos IFs. Além da integração das antigas instituições de ensino técnico, novos câmpus ligados aos IFs foram criados. São 40 novos câmpus em 25 das 35 microrregiões do estado.

\section{Resultados da política de expansão no RS}

Desagregando o número total de cursos pelas grandes áreas do conhecimento, é possível perceber as nuances da expansão no estado. Observa-se que a grande área de Agricultura e Veterinária, que engloba cursos como Agronomia, Medicina Veterinária, Zootecnia e cursos ligados principalmente ao setor 
primário, teve significativo incremento. Antes de 2003, eram 8 cursos de graduação desta grande área ofertados em instituições federais de ensino superior e técnico no estado. Todos os cursos de Agronomia e Veterinária, criados antes de 2003, foram iniciados antes de 1973. Desse total, 3 eram ofertados pela UFSM; 3 pela UFPel, sendo 2 em Capão do Leão e 1 em Pelotas; e 2 pela UFRGS. Após 2003, foram criados 32 novos cursos dessa área, que passaram a atender 12 novas microrregiões. A UFSM aumentou sua atuação para as microrregiões de Carazinho, Frederico Westphalen e Restinga Seca; a UFPel criou um novo curso em Pinheiro Machado, na microrregião de Serras de Sudeste. Os 4 cursos criados pela FURG, dois na microrregião de Litoral Lagunar e dois na de Osório, estão de alguma forma ligados à indústria, são eles: Engenharia agroindustrial (indústria alimentícia) e Engenharia Agroindustrial (agroquímica). O valor adicionado dessas regiões destaca-se por ser majoritariamente composto pela indústria e a criação de vagas em cursos de graduação nessa área tende a contribuir com a formação de recursos humanos e, futuramente, com a pesquisa para seu fortalecimento.

Além do processo de expansão de cursos na área de Agronomia e Veterinária, há também um processo de desconcentração na oferta desses cursos. A microrregião da Campanha Ocidental que antes da política não contava com a oferta de nenhum desses cursos, atualmente oferta 7, sendo 4 no Alegrete, $2 \mathrm{em}$ Uruguaiana e 1 em Itaqui. A região é a que participa com maior parte do valor adicionado da agricultura $(6,9 \%)$ e esse movimento de expansão e desconcentração promovido pela política tem grande potencial para ofertar recursos humanos para essa área.

Os cursos de Ciências Sociais Aplicadas, Negócios e Direito se concentravam predominantemente em Santa Maria e Porto Alegre. Eram até então ofertados no estado 33 cursos dessa área, todos na modalidade de bacharelado. Atualmente o estado conta com 78 cursos dessa área, ou seja, foram iniciados 45 novos cursos no RS, sendo 9 tecnológicos. Essa área engloba cursos como, Administração, Comércio Exterior, Contabilidade e Economia, que dão bases para desenvolvimento de novos empreendimentos e negócios. Os novos cursos avançaram principalmente em direção à porção Norte-noroeste do estado

Cursos ligados à área de Engenharias, Produção e Construção apresentaram um crescimento significativo tanto nas tradicionais instituições de ensino superior do estado (UFRGS, UFPel, UFSM e FURG), como nas recém-criadas (UFFS, Unipampa, IF-Farroupilha, IFRS e IFSul). Após 2003, há um intenso movimento em direção à criação de novos cursos: 84 no total, sendo 66 em bacharelados e 18 tecnológicos, ofertados na FURG, UFPel e UFSM, IF-Farroupilha e a IFSul. Os cursos continuam sendo ofertados majoritariamente pelas instituições tradicionais, mas passaram a ser oferecidos em praticamente toda a porção Sul do estado, com a Unipampa, e no Norte com a expansão geográfica da UFSM para Frederico Westphalen e a recém-criada UFFS. Ressalta-se que regiões tradicionalmente industriais, como Santa Cruz do Sul e Caxias do Sul não receberam novos cursos dessa área.

Até 2003, eram 24 os cursos na área de Ciências, Matemática e Computação, sendo 9 em Porto Alegre, 6 em Santa Maria, 5 em Pelotas e 4 na microrregião do Litoral Lagunar, todos bacharelados. Após esse período, foram criados 57 novos cursos: 28 bacharelados, 28 tecnológicos e 1 licenciatura. Os novos cursos passaram a atender 15 novas microrregiões do estado. A instituição que mais criou cursos foi o IFRS, 11 no total. Após 2003, o estado passou a contar com 81 cursos de graduação ligados à esta área, sendo 51 bacharelados, 2 licenciaturas e 28 tecnológicos. A maioria ofertados na microrregião de Porto Alegre, pela UFRGS, UFCSPA, UFPel e IFRS.

Farmácia, o primeiro curso da grande área de Saúde e Bem-Estar Social do Rio Grande do Sul, teve início em 1895 na UFRGS. Este é um dos 23 cursos dessa grande área criados antes de 2003 no estado. Nesse período, os cursos desta área estavam dispostos da seguinte maneira: 8 em Pelotas, sendo 6 bacharelados e 2 tecnológicos; 7 em Santa Maria, todos bacharelados; 6 em Porto Alegre, todos bacharelados; e 2 em Rio Grande, ambos bacharelados. Grande parte dos cursos foi criada antes da década de 1980. A partir de 2003, são iniciados 49 novos cursos, sendo 32 bacharelados e 17 tecnológicos. A concentração na microrregião de Porto Alegre se justifica pela criação, em 2008, da UFCSPA, que oferta $60 \%$ das vagas da área de Saúde e Bem-Estar Social. Com o fim da política de expansão, os cursos de Saúde e Bem-Estar Social passaram a ofertar cursos em 11 microrregiões do estado. 
A área de Humanidades e Artes contava com 19 cursos no estado antes de 2003, a maioria deles criada na década de 1970 na UFPel, instituição que até então ofertava o maior número deles no Rio Grande do Sul. De 2003 até 2016, foram criados 26 novos cursos, dos quais apenas 3 em novas instituições: 2 na IFSul e 1 na Unipampa. Em termos da expansão territorial, a criação de cursos de Humanidades e Artes avançou apenas para uma nova microrregião, com um novo curso de História da Unipampa na microrregião de Jaguarão. Essa área foi uma das que menos cresceu no estado, tanto em número de cursos como na extensão territorial, evidenciando que o caráter da política estava assentado na expansão de cursos e vagas ligados diretamente ao setor produtivo.

A grande área de Educação foi a que recebeu maior número de novos cursos em termos absolutos. Foram 83 entre os anos de 2003 e 2016, sendo que dois deles ainda não foram iniciados. As microrregiões de Santa Maria e Pelotas foram as que apresentaram maior crescimento nesses cursos. Dessa forma, essas regiões concentram juntas mais de $40 \%$ da oferta de cursos de Educação do estado. Por outro lado, o aumento no número desses cursos em outras instituições permitiu que a oferta avançasse para outras microrregiões. A instituição responsável por esse espraiamento da oferta de cursos por todo o estado é a Unipampa, que, a partir de sua criação em 2008, originou novos câmpus em várias microrregiões do estado.

Outro braço da política foi a expansão da pós-graduação. No estado do Rio Grande do Sul esse crescimento, apesar de menor que no Brasil (119\%), foi significativo: de 102 programas, em 2001, passouse para 239, em 2016. O maior crescimento de programas de pós-graduação no estado, em termos absolutos, ocorreu na microrregião de Pelotas, onde atuam a UFPel e o IFSul. Em 2001, a microrregião contava com 11 programas, dos quais 7 se concentravam na área de "Ciências Agrárias", 2 de "Ciências da Saúde" e, "Ciências Exatas e da Terra" e "Ciências Humanas" tinham 1 programa cada. Em 2016, o número de programas salta para 45, um aumento de 309\%. A área de "Ciências Agrárias" ganhou 5 novos programas, somando 12. A área de "Ciências Humanas" que contava com apenas um programa em 2001, passou a contar com 8 e é atualmente a segunda grande área com mais programas na microrregião. Há ainda, uma importante expansão de cursos multidisciplinares na região, que em 2001 não contava com programas deste tipo, mas em 2016 passou a sediar 7 deles.

O crescimento dos programas de pós-graduação tem influência direta no crescimento dos grupos de pesquisa. O crescimento do número de grupos de pesquisa foi da ordem de $160 \%$ e daqueles que relataram relacionamentos de $676 \%$. Dessa forma, o grau de interação, medido pela relação do número de grupos que relataram relacionamentos com o número total de grupos de pesquisa, subiu de $11 \%$ para $32,7 \%$, ou seja, praticamente $1 / 3$ dos grupos de pesquisas em atividade se relacionam de alguma forma com outras instituições. O aumento substancial no número de grupos de pesquisa com relacionamento com outras organizações se deu por dois motivos. Primeiro, um aumento substancial desses grupos nas universidades já instaladas e, segundo, pelo surgimento de grupos de pesquisas nas universidades e institutos recémcriados. Apesar da UFRGS e a UFSM continuarem liderando o ranking do número de grupos com relacionamentos com outras instituições, com o surgimento de grupos nas novas universidades e institutos federais, essa concentração das universidades tradicionais diminuiu de 2002 para $2016^{24}$.

Em 2002, as instituições federais de ensino superior e técnico do Rio Grande do Sul se relacionaram com 205 empresas. Já em 2016 foram 761 (+670\%) com parcerias com 1.767 empresas e outras instituições. Do total de 205 empresas em 2002, 67\% eram empresas gaúchas e 33\% empresas em 10 diferentes estados do País. Figuram entre as unidades da federação com maior número de empresas com parcerias com as instituições analisadas: São Paulo (33\%), Rio de Janeiro (19\%), Paraná (13\%), Santa Catarina (12\%) e Distrito Federal (10\%). Os relacionamentos em outros estados foram feitos metade com o setor secundário e a outra metade com o setor terciário. Os relacionamentos com as empresas do setor secundário foram majoritariamente com a indústria de transformação $(70 \%)$ e, dentro dessa categoria, destacaram-se as empresas de fabricação de derivados do petróleo (13\%), de produtos químicos (13\%); de celulose (13\%) e de veículos automotores (13\%). As empresas do setor secundário que mais se relacionaram com as

\footnotetext{
${ }^{24}$ Os institutos federais, de modo geral, apresentam um número menor de relacionamentos em relação com as universidades. Isso pode ser explicado, em parte, pelo fato de as universidades possuírem um número maior de programas de pós-graduação, enquanto as IFs se dedicam mais às atividades de ensino.
} 
instituições do Rio Grande do Sul foram as do Rio de Janeiro, representando $44 \%$ do total de relacionamentos.

Em 2016, há um aumento de relacionamentos com instituições de fora do estado, de 33\% em 2002 para $44 \%$ em 2016, e passando a ocorrer com empresas e outras organizações situadas em todas as unidades federativas do País.

Na região Sudeste se localizava a maior parte das empresas e organizações que se relacionaram com os grupos de pesquisa analisados em 2016: São Paulo, representando 21,1\% do total nacional de empresas; Rio de Janeiro, 13,8\%; Minas Gerais, 6,3\%; e Espírito Santo, 1,4\%. As organizações do Sudeste que mais se relacionaram com os grupos pertenciam ao setor terciário, 265 no total (80\%). Cerca de $68 \%$ dessas relações se davam com órgãos relacionados à educação: universidades, faculdades e institutos de pesquisas. Além disso, se comparado com 2002, são intensificadas importantes relações com a indústria de transformação, que aumentou seus relacionamentos com empresas ligadas à produção de derivados do petróleo, de produtos farmacêuticos, de produtos químicos e produtos alimentícios.

O destaque da região Centro Oeste se dá graças ao importante papel do Distrito Federal, que representa $15 \%$ das parcerias. São 149 empresas com relacionamentos na região, sendo 116 só do DF. As empresas e outras organizações da região exercem fundamentalmente atividades profissionais, científicas e técnicas (34\%), administração pública, defesa e seguridade (23\%) e educação (20\%). O DF se destaca principalmente por conter importantes instituições da administração pública, maioria dos relacionamentos com os grupos analisados.

A região Nordeste que, em 2002, sediava apenas 5 empresas com relacionamentos com as instituições analisadas, passa a ser responsável por $11,5 \%$ das parcerias de fora do estado. O Ceará $(2,4 \%)$, a Bahia $(2,1 \%)$, Pernambuco $(2,1 \%)$, a Paraíba $(1,4 \%)$ e o Rio Grande do Norte $(1,4 \%)$ são os estados com maior número de relações nessa região. Para além da predominância de relações com empresas de educação, as parcerias com o Nordeste variam de atividades profissionais, científicas e técnicas (5\%), à indústria extrativa $(1 \%)$ e indústria de transformação (1\%). Assim como no Nordeste, as relações com o Norte se concentram em institutos de pesquisas, faculdades e universidades, representando $92,5 \%$ dos relacionamentos com essa região.

A região Sul - excetuando-se o Rio Grande do Sul da análise - é a maior fonte de relacionamentos para os grupos de pesquisas das instituições analisadas. Santa Catarina e Paraná correspondem a 22\% das empresas que mantêm parcerias. Assim, como no Sudeste, a maioria das organizações parceiras são do setor de serviços e ligadas de alguma forma à educação, compreendendo $85 \%$ dessas instituições. Das empresas e organizações industriais, $42 \%$ eram do setor alimentício e $6 \%$ do setor madeireiro. É difícil avaliar se houve uma melhora em termos de setores com maior ou menor complexidade que envolveram as parcerias, pois em 2002 eram poucas as empresas desses estados, mas sem dúvida aumentou o grau de diversidade dos setores de atividades.

Em síntese, cabe destacar que, além do aumento no número de grupos de pesquisa entre 2002 e 2016, houve uma diminuição relativa das parcerias com empresas e outras instituições dentro do estado do RS. Há dois movimentos que explicam essa mudança. Primeiro, há uma intensificação dos relacionamentos com organizações ligadas às universidades, faculdades e institutos de pesquisa localizados fora do estado e, nesses relacionamentos, há um troca de informações sobre pesquisas e outras atividades desempenhadas dentro das instituiçõos ${ }^{25}$. E, segundo, está havendo um fortalecimento das relações com empresas da indústria de transformação, principalmente situadas no Sudeste e em setores importantes, como a produção de derivados do petróleo e produtos químicos. De modo geral, as parcerias em outros estados ocorrem com outras organizações de educação, indicando para um fortalecimento do sistema nacional de inovação, com universidades interiorizadas em todos as regiões do País.

Os tipos de empresas e organizações com as quais as universidades e institutos federais se relacionaram, em 2016, mudaram drasticamente. Anteriormente, os grupos se relacionavam mais com empresas industriais, predominantemente da indústria de transformação; já em 2016, passaram a se

\footnotetext{
25 Além disso, esse movimento é reforçado pelas parcerias estabelecidas com outras instituições fora do País.
} 
relacionar mais com instituições do setor terciário. Cerca de 55\% do total dessas organizações estavam ligadas a atividades de educação: centros e institutos de pesquisa, faculdades. Universidades, etc. Dessa forma, é possível verificar a intensificação da formação de uma complexa rede de relacionamentos entre as universidades e institutos federais com outras universidades e centros de pesquisas do estado, inclusive com relações internas, com outras unidades das próprias instituições.

A indústria no Rio Grande do Sul como um todo, compreendeu 19\% das instituições com as quais mantiveram relacionamentos as universidades e institutos analisados. A indústria de transformação representou 79\% dessas empresas, correspondendo a um aumento de 7 p.p. na participação desse ramo de atividade nas parcerias, em relação a 2002. Os setores das empresas que mais se destacaram foram: produtos alimentícios; produtos químicos; manutenção, reparação e instalação de máquinas e equipamentos; equipamentos de informática, produtos elétricos e ópticos; celulose; e produtos farmoquímicos e farmacêuticos. Em relação a 2002, houve, portanto, uma diversificação dos ramos de atividades das firmas que têm relacionamentos no âmbito do setor secundário.

Assim como em 2002, em 2016 a instituição com maior número de parceiros foi a UFRGS; relacionando-se com 426 organizações. Desse total, 1,7\% era de empresas ou organizações do setor agropecuário, 20,4\% do setor industrial e 77,9\% do setor de serviços. Assim como analisado anteriormente, o relacionamento com outras universidades e instituições de educação e pesquisa correspondeu a $48 \%$ do total de interações. Portanto, em um primeiro momento se faz necessário dividir a análise das relações das universidades analisadas com outras instituições de educação e com as empresas. Dessa forma, excetuandose as relações com outras organizações de educação, a indústria passa a representar $39,4 \%$ dos relacionamentos, a agropecuária 3,2\% e os serviços $57,4 \%$.

A UFRGS se relacionou com organizações situadas em 20 microrregiões além daquela em que está inserida. As parcerias com organizações da indústria, se restringiram às microrregiões próximas de onde a universidade está sediada, como ocorrido em 2002. Os grupos da universidade se relacionaram com 41 organizações da indústria de transformação na microrregião de Porto Alegre, o que representa 74,5\% dos relacionamentos com essa atividade. Em Caxias do Sul, uma microrregião próxima da de Porto Alegre (onde está sediada a UFRGS) estão localizadas 3 das empresas que se relacionaram com a universidade. Guaporé, Lajeado-Estrela, Montenegro, Cachoeira do Sul, Ijuí e Passo Fundo, representaram 16,4\% dos relacionamentos da UFRGS, e são, do mesmo modo, microrregiões próximas aos grupos de pesquisa. A única microrregião relativamente longe da UFRGS que apresentou duas relações entre grupos e empresas da indústria de transformação, foi a Campanha Meridional, 2 no total. Dessa forma, a proximidade entre universidade e empresa continua se mostrando importante para o estabelecimento das interações entre universidade e indústrias de transformação.

Os relacionamentos da UFRGS com o setor primário não variaram de forma significativa. Em 2002, eram 3 as empresas que se relacionavam com a universidade e, em 2016, foram 6. Apesar de ter dobrado, a participação relativa do setor agropecuário caiu em relação aos outros. Portanto, não se mostra como uma importante fonte de interações entre grupos de pesquisas da UFRGS e o setor primário.

A UFSM foi a que apresentou o segundo maior número de relações entre grupos de pesquisas e outras instituições no estado. A instituição estabeleceu 6 parcerias com o setor primário $(2,9 \%), 46$ com o secundário $(21,9 \%)$ e 158 com o terciário $(75,2 \%)$. Colocando à parte os relacionamentos com outras organizações de educação, que representaram $65 \%$ do total de parcerias em 2016, a indústria passa a representar 52\% dos relacionamentos, a agricultura $7 \%$ e os serviços $41 \%$. Portanto, em relação a 2002, há um crescimento das parcerias com o setor industrial e com o setor de serviços, e um diminuição com o setor agropecuário. Além da diminuição das parcerias com o setor primário, em 2016, os relacionamentos da UFSM passaram a se concentrar apenas nas microrregiões de Porto Alegre e Cachoeira do Sul, além da própria microrregião onde atua a universidade.

Os relacionamentos da UFSM com o setor de indústria de transformação em 2016 se deram de forma mais diversificada que em 2002. Enquanto em 2002 os relacionamentos com essa atividade estavam concentrados em 5 microrregiões, em 2016 os grupos da universidade estabeleceram parcerias com 12 
microrregiões, além da microrregião onde está localizada. Os relacionamentos foram estabelecidos com microrregiões onde a atividade industrial se mostrou importante no valor adicionado bruto.

De forma geral, há uma diversificação da UFSM na parceria com o setor de serviços. Antes as empresas com parcerias com a UFSM atuavam em no máximo 4 atividades do setor terciário, em 2016, afora o grande volume com outras instituições de educação e pesquisa, a universidade diversificou suas relações com o setor terciário, se relacionando agora com o setor de informação e comunicação, com atividades imobiliárias, serviços de saúde humana e serviços sociais, dentre outros. E, ainda, não há um padrão de relacionamento por microrregião. Não sendo relevantes, portanto, a proximidade geográfica ou a especialização da microrregião para explicar as interações.

$\mathrm{Na}$ UFPel a estrutura das parcerias com outras instituições segue o mesmo padrão das outras universidades, qual seja, a predominância das interações com o setor terciário e a menor relação com o setor agropecuário. Em grande parte, devido ao grande número de relacionamentos com outras instituições de educação, como já analisado.

Em 2016, os relacionamentos dos grupos de pesquisa da UFPel com outras instituições ligados à educação corresponderam a $75 \%$ do total de interações com o setor terciário. Colocando os relacionamentos com essas organizações à parte e analisando os relacionamentos com as empresas, é possível perceber um crescimento da importância das relações com as empresas industriais gaúchas. Em 2002 a indústria representou 41,2\% dos relacionamentos com grupos de pesquisas da UFPel, já em 2016 esse número sobre para $47,1 \%$. Esse aumento se dá predominantemente na indústria de transformação, mais especificamente a indústria alimentícia e a de fármacos.

Em 2002, os relacionamentos da UFPel com a indústria de transformação se limitavam à sua própria microrregião e a um relacionamento com a microrregião de Camaquã. Em 2016, a universidade passou a se relacionar com 6 novas microrregiões: Caxias do Sul, Litoral Lagunar, Montenegro, Passo Fundo, Porto Alegre e Santa Maria. Os relacionamentos com o setor primário também cresceram para outras microrregiões, como Passo Fundo, Osório e Jaguarão.

O número de interações da FURG com outras instituições localizadas no estado do RS cresceu substancialmente. A maior parte desse crescimento é resultado de um crescimento das relações com outras instituições de educação. O relacionamento com essas organizações representou $70 \%$ das parcerias estabelecidas pela FURG em 2016. Dessa forma, fazendo o mesmo exercício de análise feito anteriormente, colocando à parte esses relacionamentos da investigação, há um crescimento da participação do setor industrial nos relacionamentos da universidade. Em 2002, a indústria representava $36 \%$ das relações dos grupos de pesquisa da universidade, e, em 2016, passa a ser 47,8\%. A indústria de transformação é a mais importante para esses relacionamentos, destacando-se a indústria alimentícia e a fabricação de produtos derivados do petróleo e biocombustíveis, bem como a fabricação de produtos químicos. Os relacionamentos com a indústria de transformação foram feitos fundamentalmente na própria microrregião do Litoral Lagunar, onde a universidade está instalada, 4 no total (40\%).

O número de parcerias com o setor primário continua o mesmo em números e no destino da relação. Com relação ao setor de serviços (excetuando-se a relação com instituições de educação), a estrutura se manteve basicamente a mesma de 2002 para 2016, aumentando apenas o número de interações com a administração pública.

Na Unipampa, com câmpus em vários municípios do estado, os grupos de pesquisas se relacionaram com 70 organizações. Desse total, $81 \%$ com o setor terciário, $14 \%$ do setor secundário e $4 \%$ do setor primário. As interações com outras universidades e institutos de pesquisas representam $70 \%$ de todas as parcerias estabelecidas pela universidade. Excetuando as relações com outras instituições de ensino, a interação com o setor secundário representa $50 \%$ das relações.

A Unipampa se relaciona com indústrias extrativas (3), indústria de transformação (3), indústria de eletricidade e gás (3) e construção (1). Os relacionamentos com a indústria extrativa ocorrem na sua totalidade com empresas que exercem atividades de extração de minerais não metálicos, na microrregião de Porto Alegre, de Serras do Sudeste e de Frederico Westphalen. Os relacionamentos com a indústria de transformação acontecem na indústria alimentícia, empresas fabricantes de produtos de minerais não- 
metálicos e fabricantes de produtos de metal, exceto máquinas e equipamentos; que ocorrem com empresas da Campanha Ocidental e Serras do Sudeste. Os relacionamentos com a indústria de eletricidade e gás ocorrem com empresas da microrregião de Porto Alegre, Passo Fundo e Restinga Seca.

Os relacionamentos com a agropecuária representam $15 \%$ das parcerias dos grupos de pesquisas da Unipampa. Esses relacionamentos ocorrem na microrregião da Campanha Ocidental e de Porto Alegre. O setor terciário (excetuando-se as parcerias com outras universidades e institutos de pesquisa), representa $35 \%$ dos relacionamentos, variando entre empresas ligadas ao comércio, reparação de veículos automotores, instituições ligadas à administração pública e àquelas que exercem atividades profissionais, científicas e técnicas. A Unipampa se relacionou com 13 microrregiões, um resultado surpreendente para uma instituição com poucos anos de existência. Excluindo as 50 instituições de educação da análise, a Unipampa passaria a ter 20 relacionamentos com 7 microrregiões, desempenho muito próximo do que tinha a UFSM em 2002.

Os relacionamentos estabelecidos pelos grupos de pesquisas da UFCSPA se limitaram, em 2016, ao setor de serviços. Das 30 parcerias com outras instituições do RS, 23 foram com outras universidades e institutos de pesquisa e, as outras 7, com instituições ligadas aos serviços de saúde humana, basicamente atendimento hospitalar.

Os IFs do estado, IF-Farroupilha, IFRS e IFSul, se relacionaram em 2016 majoritariamente com organizações do setor terciário. A parceria com outras universidades e institutos de pesquisas correspondeu a 74\% de todos os relacionamentos realizados com instituições no RS. Excluindo esse tipo de relação da análise, o setor terciário ainda é mais importante que os demais. Cerca de $75 \%$ dos relacionamentos dos IFs dentro do estado são com organizações do setor de serviços. Ressalta-se a forte relação com empresas do setor de saúde humana e serviços sociais, com quase metade das parcerias do setor de serviços. Os relacionamentos com a indústria estão conformados em três empresas diferentes da indústria de transformação: duas delas em Caxias do Sul, uma dedicada à fabricação de bebidas e a outra à fabricação de calçados; e uma em Santa Cruz, dedicada à fabricação de produtos de borracha. Os relacionamentos com o setor agropecuário são menos relevantes, e foram estabelecidos com duas organizações, uma na microrregião de Porto Alegre e outra na da Campanha Ocidental.

Assim, as novas instituições de ensino superior e técnico criadas entre 2003 e 2014 se relacionam mais, proporcionalmente, com empresas e outras organizações gaúchas do que as instituições tradicionais. As universidades tradicionais, criadas antes de 2003, somaram 1.543 relacionamentos em 2016, sendo 717 com as organizações fora do estado (46\%) e 826 com as gaúchas (53\%). Já as novas instituições, relacionaram-se com 60 empresas e organizações fora do estado (27\%) e 164 no Rio Grande do Sul (73\%). Apesar disso, os relacionamentos das novas instituições, tanto com organizações de fora como de dentro do estado, foram superiores a $80 \%$ com instituições do setor terciário, majoritariamente com instituições ligadas à educação: outras universidades, faculdades e institutos de pesquisa. Por outro lado, as instituições tradicionais se relacionam proporcionalmente mais com empresas industriais, sejam elas dentro do estado ou não. E esse relacionamento com empresas do setor secundário se dá mais em direção àquelas pertencentes à indústria de transformação.

Em síntese, é possível perceber quatro importantes movimentos no que tange aos relacionamentos dos grupos de pesquisa com empresas e outras organizações. Primeiro, um aumento expressivo das interações com outras instituições ligadas à educação, como universidades, institutos e centros de pesquisa, etc. Essa nova dinâmica pode estar sendo causada inclusive pela própria expansão do ensino superior e técnico no País, que pode estar estimulando as novas instituições de ensino superior e técnico a se relacionarem com outras organizações. Segundo, um aumento importante nos relacionamentos dos grupos de pesquisa com empresas e outras organizações do setor secundário, inclusive com o aumento da diversidade com os subsetores. Terceiro, diversificação das relações com empresas e outras instituições em outras microrregiões do estado. De modo geral, os grupos de pesquisa passaram a se relacionar com um número maior de instituições localizadas em outras microrregiões, isso pode estar ocorrendo pela maior capilaridade que a interiorização do ensino superior e técnico provocou nos anos de implementação da política. E, quarto, verificou-se que as universidades e institutos federais recém-criados, isto é, Unipampa, 
UFFS, UFCSPA, IFRS, IFSul e IF-Farroupilha, se relacionam mais, relativamente, com empresas e outras organizações localizadas no estado do que as instituições tradicionais, como UFRGS, UFSM, UFPel e FURG. Essa nova dinâmica pode ser explicada pelo fato das novas instituições já terem sido criadas com o objetivo do desenvolvimento regional.

\section{Considerações Finais}

Em síntese, observou-se que o processo de interiorização se deu de forma efetiva no estado. Isso porque os cursos de ensino superior passaram a atender $74 \%$ das microrregiões do estado, sendo que até 2002 atendiam apenas $11 \%$. Identificou-se nessa nova dinâmica, o papel central que desempenha as novas universidades, especialmente a Unipampa e a UFFS, no desenvolvimento da localidade em que estão inseridas. A criação dos IFs foi também de suma importância para o ensino técnico, visto que foram responsáveis pela criação de quase metade (43\%) dos cursos tecnológicos.

De forma geral, os cursos de graduação criados após 2003, no bojo da política, ajudaram na desconcentração da oferta de ensino superior e técnico público em direção a regiões de menor renda per capita no estado. A grande maioria dos cursos foi criada contemplando as atividades produtivas características de suas regiões. Vale citar como por exemplo os cursos ligados à "Agricultura e Veterinária", criados majoritariamente em regiões que contribuem substancialmente para o valor adicionado da agricultura do estado. Em outros casos, a política atuou claramente no sentido de possibilitar o desenvolvimento de setores não tão tradicionais para a região, como no caso dos cursos ligados à área de "Engenharias, Produção e Construção", criados em grande medida na metade Sul do estado, região historicamente mais pobre que o Norte do RS. Outro resultado relevante é a criação de cursos ligados à área de "Educação", que tem por objetivo a formação de novos educadores nas diversas áreas do conhecimento. Nessa área, os cursos foram criados em várias partes do estado e puderam contribuir, em um primeiro momento, para atenuar a migração do interior para a capital e, posteriormente, para estimular a formação de recursos humanos mais qualificados.

Com relação à criação de novos programas de pós-graduação, apesar de pequenos em valores absolutos, os números da expansão no interior indicam que as novas universidades e institutos federais estão criando mais programas, relativamente, que as instituições tradicionais. Dessa forma, um interessante resultado analisado é a desconcentração geográfica dos programas de pós-graduação no estado. Essa nova dinâmica regional, isto é, maior qualificação e profissionalização de recursos humanos em outras partes do estado, tem resultados diretos no fortalecimento da infraestrutura científica do RS.

Em 2016, já com alguns resultados da política aflorando - como o crescimento dos programas de pós-graduação e a consequente maior qualificação dos participantes de grupos de pesquisa - é possível notar uma mudança na dinâmica de relacionamentos entre as instituições federais de ensino superior e técnico do estado e outras instituições. Não é possível afirmar de forma categórica, mas esse crescimento dos relacionamentos com outras instituições de educação pode ter sido estimulado e reforçado através do crescimento do número de câmpus e universidades por todo território do País. E, se essa hipótese for comprovada, é possível que o sistema nacional brasileiro também esteja passando por um processo semelhante de amadurecimento, em direção à pesquisa básica e ao alargamento da base de conhecimento do País.

Apesar do resultado extraordinário, em termos de relacionamento das universidades e institutos federais recém-criados com a política de expansão, as parcerias com o setor secundário se dão em maior volume com as instituições tradicionais. Uma possível resposta para essa dinâmica estaria na relação entre o grau de amadurecimento das universidades e institutos federais e as parcerias estabelecidas. Ou seja, instituições tradicionais, por terem uma estrutura física, de know-how, de relacionamentos, etc., elementos que exigem tempo para sua construção, conseguiriam estabelecer mais facilmente interações com o setor secundário do que aquelas recém-criadas, que ainda estão desenvolvimento sua institucionalidade.

Enfim, verificou-se que a hipótese do trabalho foi confirmada. Isto é, a política de expansão do ensino superior e técnico no Brasil ao promover a interiorização das universidades, alcançou uma maior 
qualificação da infraestrutura técnico-científica e uma intensificação das relações entre os agentes, e essa combinação de fatores está contribuindo para o fortalecimento do sistema inovativo gaúcho.

\section{Referências Bibliográficas}

BONACCORSI, A; PICCALUGA, A. A theoretical framework for the evaluation of university-industry relationships. R\&D Management, Oxford, v. 24, n. 3, p. 229-247, 1994.

BRASIL, Lei n. 10.172, de 9 jan. de 2001. Plano Nacional de Educação, Brasília, DF, jan 2001.

BRASIL. MINISTÉRIO DA EDUCAÇÃO. Secretaria de Ensino Superior. A democratização e expansão da educação superior no país: 2003-2014 (Balanço Social 2003 2014). Brasília, DF, 2015.

BRASIL. Ministério da Educação. Expansão da Rede Federal. Brasília, DF, 2016. Disponível em: <http://redefederal.mec.gov.br/expansao-da-rede-federal>. Acesso em: 08 set 2017,

CONSELHO NACIONAL DE DESENVOLVIMENTO CIENTÍFICOS E TECNOLÓGICO DGP/CNPQ. Diretório dos Grupos de Pesquisa do CNPq. Brasília, 2017. Disponível em: <http://lattes.cnpq.br/web/dgp>. Acesso em: 28 ago 2017.

DE MELLO, J. M. C.; MACULAN, A. M.; RENAULT, T. B. Brazilian universities and their contribution to innovation and development. In: Universities in transition. Springer New York, 2011. p. 53-76.

DINIZ, C. C. Dinâmica regional e ordenamento do território brasileiro: desafios e oportunidades.

[S.1.], Cedeplar, Universidade Federal de Minas Gerais, 2013. Disponível em:

<http://www.cedeplar.ufmg.br/pesquisas/td/TD\%20471.pdf>. Acesso em:28 out 2017.

DOUTRIAUX, J. Knowledge clusters and university-industry cooperation. In: KARLSSON, C.

Handbook of Research on Innovation and Cluster: Cases and Policies. Northampton, 2008. p. 149166.

FAGNANI, E. A política social do Governo Lula (2003-2010): perspectiva histórica. SER Social, Brasília, v. 13, n. 28, p. 41-80, 2011.

INSTITUTO BRASILEIRO DE GEOGRAFIA E ESTATÍSTICA - IBGE. Instituto Brasileiro de Geografia e Estatística. Rio de Janeiro, Disponível em: <https://www.ibge.gov.br/>, 2017. Acesso em:07 set 2017.

INSTITUTO BRASILEIRO DE GEOGRAFIA E ESTATÍSTICA - IBGE. Divisão regional do Brasil em regiões geográficas imediatas e regiões geográficas intermediárias: 2017. 1. ed. Rio de Janeiro: [s.n.], 2018. 82 p. v. 1.

LIND, F.; STYHRE, A.; AABOEN, L. Exploring university-industry collaboration in research centres. European Journal of Innovation Management, [S.1.], v.16, n. 1, p.70-91, 2013.

LUNDVALL, B. The university in the learning economy. Presentation on the Future role of Universities, Strasbourg, v. 26, 2002.

MOWERY, D. C.; SAMPAT, B. N. Universities in national innovation systems. In: FARGERBERG, J.; MOWERY, D.C.; NELSON, R.R. The Oxford handbook of innovation. New York: Oxford University Press, p.209-239, 2007. 
NELSON, R. R. National innovation systems: a retrospective on a study. Industrial and corporate change, v. 1, n. 2, p. 347-374, 1992.

PAVITT, K. The social shaping of the national science base, Research Policy, Amsterdam, 27(8): 793805, 1998.

PIRNAY, F.; SURLEMONT, B.; NLEMVO, F. Toward a typology of university spin-offs. Small business economics, Dordrecht, v. 21, n. 4, p. 355-369, 2003.

PORTER, M.E.; STERN, S. Innovation: location matters. MIT Sloan Management Review. Cambridge, v. 42, n. 4, p. 28, 2001.

SALTER, A; et al. Talent, not Technology: Publicly Funded Research and Innovation in the UK, SPRU, London: CVCP, 2000.

VELHO, L. Projeto Estudo Comparativo dos Sistemas de Inovação no Brasil, Rússia, Índia, China e África do Sul-BRICS. Formação de Mestres e Doutores e Sistema de Inovação. Rio de Janeiro, 2007. 